\title{
Nuvem de tags como ferramenta de análise de conteúdo: uma experiência com as cenas estendidas da telenovela Passione na internet
}

\author{
Ligia Maria Prezia Lemos ${ }^{1}$
}

\begin{abstract}
Resumo: Uma das iniciativas de criação de narrativa transmídia da TV Globo foi a realização e disponibilização apenas no site de cenas exclusivas da telenovela Passione (2010), as chamadas cenas estendidas. Esse artigo analisa tais cenas a partir da questão dos gêneros do discurso (BAKHTIN, 2010) e, com base em sua transcrição, propõe uma experiência de aplicação do sistema de nuvem de tags enquanto ferramenta de manuseio de dados textuais com o objetivo de realizar análise de conteúdo (BARDIN, 2011).

Palavras-chave: ficção televisiva brasileira; nuvem de tags; gêneros do discurso.
\end{abstract}

\begin{abstract}
TV Globo, with the telenovela Passione (2010) presented an initiative to create transmedia narrative: the performance and availability of scenes only on the site, called extended scenes. This article analyzes such scenes from the question of discourse genres (BAKHTIN, 2010) and, based on its transcript, proposes an application experience of tag cloud system while handling tool of textual data in order to perform content's analysis (BARDIN, 2011). Keywords: Brazilian television fiction; tag cloud; discourse genres.
\end{abstract}

\section{Introdução}

As narrativas transmídia nasceram de uma expansão técnica e mercadológica que trouxe também a necessidade de alargamento das telas narrativas, ou seja, gerou uma busca estética que oferecesse suporte para tal ambiente no sentido de ampliar a relação do público com a história e com os personagens ficcionais (JENKINS, 2009). A transmídia storytelling, sua denominação em inglês, apresenta, portanto, uma contribuição única em cada meio e funciona como um grande baú que contém as informações subjetivas da história, como se fossem papéis, fotos, diários, vestígios e lembranças que se apresentam à memória para gerar um todo narrativo.

${ }^{1}$ Doutoranda em Ciências da Comunicação pela Escola de Comunicações e Artes da Universidade de São Paulo, ECA, USP. E-mail: ligia.lemos@usp.br. 
A telenovela Passione, da Rede Globo, exibida de maio de 2010 a janeiro de 2011, apresentou um exemplo significativo de experimentação de narrativa transmídia na ficção televisiva brasileira com as cenas estendidas no site da telenovela. Essas cenas representaram um "ensaio" de criação de linguagem, inaugurando questionamentos em uma época notadamente marcada por alterações nos papéis do emissor, do receptor e dos meios de comunicação.

O trabalho a seguir propõe uma metodologia de sistematização para o uso de nuvens de $\operatorname{tags}^{2}$ como ferramenta de operacionalização da análise de conteúdo de cenas ficcionais. Para Bardin (2011: 15), a análise do conteúdo é um método empírico, um conjunto de instrumentos em constante refinamento, que se aplica a discursos diversificados e que se refere, principalmente, à descrição objetiva, sistemática e quantitativa do conteúdo, sem, por isso, deixar de ser uma análise de significados.

A telenovela Passione foi escrita por Sílvio de Abreu para quem toda a trama está relacionada à protagonista, Bete Gouveia, interpretada pela atriz Fernanda Montenegro. Segundo ele,

Bete Gouveia é o eixo de toda a trama. Tudo acontece porque aos 75 anos ela descobre que tem um filho. E essa descoberta modifica a vida de todos os personagens, que de uma maneira ou de outra, estão ligados a essa história. Apesar dos vários núcleos e personagens, a novela conta uma única história. Não é uma novela de tramas paralelas. As tramas são todas convergentes. Este é o grande diferencial entre 'Passione' e as outras novelas. Tudo é interligado. ${ }^{3}$

Entre os atores principais, destacamos Fernanda Montenegro, Tony Ramos, Mariana Ximenes, Reynaldo Gianecchini, Carolina Dieckmann, Rodrigo Lombardi, Marcello Antony, Werner Schünemann, Francisco Cuoco, Irene Ravache e Aracy Balabanian. Os núcleos de personagens localizavam-se no

${ }^{2}$ Utilizamos nesse trabalho o termo tag como sinônimo de rótulo ou etiqueta, para fins de categorização.

3 Fonte: Na novela Passione, todos os caminhos levam a Bete Gouveia. Coluna Flávio Ricco. UOL Entretenimento. 20 de junho de 2012. Disponível em: http://televisao.uol.com.br/colunas/flavio-ricco/2010/o6/20/na-novela-passionetodos-os-caminhos-levam-a-bete-gouveia.jhtm. Acesso em abr. de 2012. 
Brasil, em São Paulo e na Itália, na Toscana. Além das relações familiares, como temáticas predominantes de Passione, tivemos "ambição, disputa pelo poder no mundo empresarial, vingança, falsidade ideológica, troca de identidades, revelação de identidade, bastardia, adultério, compulsões, assassinatos e adoção de crianças abandonadas" (LOPES, 2011: 158), ou seja, os temas tradicionais e recorrentes do melodrama televisivo. A partir do segundo terço de sua exibição, a trama passou a utilizar a narrativa predominantemente policial com o recurso do Quem matou? Na internet,

O site de Passione foi pioneiro tanto em termos de oferecer maior interatividade em jogos e enquetes do que o proporcionado por telenovelas anteriores, quanto por criar conteúdo ficcional em vídeo, exclusivo para a internet, disponibilizando as cenas estendidas, não apresentadas na TV, com os personagens dirigindo-se diretamente ao espectador. Em termos de narrativa transmidiática dessa obra, numa visão geral, salientamos a participação dos personagens em redes sociais (Twitter, Facebook, Orkut), aplicativos para navegação em celulares e exibição dos capítulos adaptados para mídia exterior ( $T V$ Bus Midia) (LEMOS, 2012, p. 64).

Apesar de apresentar números instáveis de audiência, Passione esteve entre os dez títulos mais vistos do ano de 2010 (terceiro lugar), com uma audiência média de $35,8 \%$ e $57,7 \%$ de share, segundo dados Obitel/Ibope (LOPES \& OROZCO, 2011, p. 155).

\section{Cenas estendidas de Passione na internet e gêneros do discurso}

Entre as ações do plano de transmídia da Globo para Passione, no sentido de ampliar o uso e realizar experimentação com ferramentas de convergência e interatividade, foram produzidas para o site da novela as cenas estendidas, inseridas na aba "conteúdo exclusivo" dos capítulos diários. Apresentadas, portanto, apenas na internet, essas cenas continham depoimentos dos personagens - e não dos atores - em formato de monólogo, sobre alguma situação do enredo, ou determinado sentimento ou, ainda, sobre algum questionamento intelectual daquela figura da obra dramática. Esses vídeos curtos, com duração média de trinta segundos a um minuto, traziam esses testemunhos ficcionais quase diários e aparentemente sem uma regra 
rígida quanto ao número de cenas estendidas ou quanto à escolha desses personagens. $\mathrm{O}$ ponto em comum desses vídeos seria a tentativa de cumprir o critério da subjetividade proposto por Jenkins (2009) para a transmedia storytelling e que significaria a abertura de acesso para diferentes pontos de vista sobre os eventos apresentados na estrutura dramática. Estrutura em processo de transformação, com limites narrativos se tornando mais tênues entre uma e outra mídia e, dessa maneira, permitindo novas experiências:

T.S. Eliot usou a expressão correlativo objetivo para descrever a maneira pela qual séries de eventos nas obras literárias podem capturar a experiência emocional. $\mathrm{O}$ computador nos permite criar correlativos objetivos para refletir sobre os muitos sistemas dos quais participamos, que observamos e imaginamos (MURRAY, 2003, p. 96).

Ao observar as cenas estendidas, nos aproximamos dos gêneros do discurso com os enunciados e seus tipos que, segundo Bakhtin (2010) são como correias de transmissão entre a história da sociedade e a história da linguagem, pois todo fenômeno novo (fonético, lexical, gramatical) precisa percorrer "um complexo e longo caminho de experimentação e elaboração de gêneros e estilos" (Bakhtin, 2010) para, assim, poder integrar o sistema da língua. Testemunhamos atualmente no próprio seio dos gêneros do discurso as mudanças, atualizações que surgem ao lado de certa instabilidade que busca pelo futuro, que procura unir o já estabelecido com o instável, o novo, o que está brotando. Não é um movimento de instabilidade vão, é uma abertura para novas possibilidades, novos enunciados, novas formas e, certamente, novas atividades humanas. É a resposta, o diálogo da vida da linguagem com a vida das atividades e significados. Responsividade, dialogismo, alteridade. Esse é o movimento orgânico que renova os gêneros, pois é o mesmo movimento que renova as atividades humanas.

Diferentemente das ficções analisadas por Jenkins (2009) como as estadunidenses Matrix e Guerra nas Estrelas ou, ainda, a britânica Harry Potter, a telenovela brasileira possui características peculiares e carrega em sua 
essência aquela representação de uma comunidade imaginada (Anderson, 2008). Considerada

como experiência de sociabilidade, ela aciona mecanismos de conversação, de compartilhamento e de participação imaginária. $A$ novela tornou-se uma forma de narrativa sobre a nação e um modo de participar dessa nação imaginada. Os telespectadores se sentem participantes das novelas e mobilizam informações que circulam em torno deles no seu cotidiano (LOPES, 2004, p. 30).

As redes sociais, as mídias exteriores, enfim, as múltiplas plataformas ampliam ainda mais esses mecanismos de conversação e de circulação da telenovela no cotidiano do brasileiro.

Para Bakhtin (2010), a linguagem efetua-se a partir de enunciados proferidos pelos integrantes de diferentes campos da atividade humana. Esses campos especificam o conteúdo e o estilo do que é dito, mas, acima de tudo, tais campos especificam sua construção composicional. Cada campo elabora, ainda, "tipos relativamente estáveis de enunciado, os quais denominamos gêneros do discurso":

A riqueza e a diversidade dos gêneros do discurso são infinitas porque são inesgotáveis as possibilidades da multiforme atividade humana e porque em cada campo dessa atividade é integral o repertório de gêneros do discurso, que cresce e se diferencia à medida que se desenvolve e se complexifica um determinado grupo (BAKHTIN, 2010, p. 262).

Os gêneros do discurso possuem uma enorme heterogeneidade e, independentemente de sua funcionalidade, podem ser diferenciados entre gêneros do discurso primários, ou simples, e secundários, ou complexos. Nos gêneros complexos observam-se a incorporação e a re-elaboração dos primários (simples). Em um primeiro momento, portanto, consideramos as cenas estendidas de Passione como um enunciado do gênero secundário, ou complexo, pois se refere à ficção televisiva propriamente dita (que por si só já se mostra como gênero complexo) a qual se acrescentam as múltiplas plataformas e suas condições e finalidades específicas.

Em termos de estilística, por categorizarmos as cenas estendidas enquanto uma exceção proposta por Bakhtin (2010), ou seja, como pertencente ao gênero "artístico-literário", podemos dizer que o estilo individual faz parte do 
enunciado e o autor - ou autores, não sabemos - de tais cenas estendidas revela o que se poderia chamar de "colorido dentro da linha", por manter, conservar e não sair da linha narrativa, ou plott, (e da construção dos personagens) elaborada pelo autor da telenovela, Sílvio de Abreu e pelos atores intérpretes desses papéis na TV e na internet.

Fica claro, portanto, que abordamos aqui a construção de um discurso narrativo que não se atém aos padrões lingüísticos per se, pois pretende enxergar a linguagem da ficção em múltiplas plataformas como um sistema dinâmico e complexo que alcança seu sentido a partir da soma das condições sociais e tecnológicas de nossa época. As cenas estendidas de Passione pertencem à paisagem desse caminho de experimentação referente ao espalhamento da ficção televisiva por múltiplas plataformas e "a passagem do estilo de um gênero para outro não só modifica o som do estilo nas condições do gênero que não lhe é próprio como destrói ou renova tal gênero" (Bakhtin, 2010: 268). Essas cenas pertencem a um sistema de linguagem que pretende contar e ampliar as histórias ficcionais de nosso tempo pelos meios agora disponíveis. Com a narrativa estendida, exclusiva para a internet, porém integrada à trama, a telenovela Passione reforça o pensamento de Motter e Mungioli (2006) de que $a$ serialidade contém ingredientes que se articulam de maneira interna e externa ao próprio produto.

Para Bakhtin, se o enunciado é a unidade da comunicação discursiva, a unidade da língua seria a oração. Sem nos determos na questão linguística da natureza da oração que, ele frisa, abriga uma forte luta de opiniões, seguimos adiante com seu pensamento que indica "para nós importa definir com precisão a relação da oração com o enunciado" (BAKHTIN, 2010, p. 277). Assim, o conteúdo das múltiplas plataformas por onde circula o enunciado Passione seriam as orações, as unidades dessa 'linguagem' que se experimenta. Bakhtin, aqui, nos dá a licença de fazer da oração um enunciado pleno e, por essa razão, enfocamos as cenas estendidas de Passione como um enunciado.

4 Para Doc Comparato (2009), Plot é a espinha dorsal da ação dramática. 
Qualquer oração pode figurar como enunciado acabado, mas, nesse caso, é completada por uma série de elementos muito substanciais de índole não gramatical, que lhe modificam a natureza pela raiz. E é essa circunstância que serve de causa a uma aberração sintática especial: ao analisar-se uma oração isolada, destacada do contexto, inventa-se promovê-la a um enunciado pleno. Consequentemente, ela atinge o grau de conclusibilidade que lhe permite suscitar resposta (BAKHTIN, 2010, p. 287).

Esse exercício de pensamento coloca as cenas estendidas de Passione como um enunciado complexo em movimento dialógico com o espectador, integrado e parte constituinte de um enunciado pleno. Os movimentos de ir em direção ao objeto e, em seguida, distanciar-se são denominados por Bakhtin (2010) de empatia e exotopia e são fundamentais para a percepção e compreensão do outro e, principalmente, para a criação do distanciamento necessário para a interlocução. Por sua atuação, os personagens de Passione chamam o espectador à cena e lhe dão o papel de confidente.

Assim, com pouca ou nenhuma movimentação de câmera, que é fixa, em ângulo frontal, horizontal; tendo pouco ou nenhum corte/edição, ou seja, em plano sequência, com enquadramento fechado em primeiro plano, nas cenas estendidas de Passione o personagem permanece parado, falando e olhando para a câmera. Selecionamos abaixo, com o intuito de confirmar as afirmações acima, sequências de imagens de dois personagens das cenas estendidas, em frames separados pelo intervalo de dez segundos. É interessante notar o olhar do personagem, sua localização/marcação e a posição da câmera que evidencia a imobilidade do cenário de fundo:
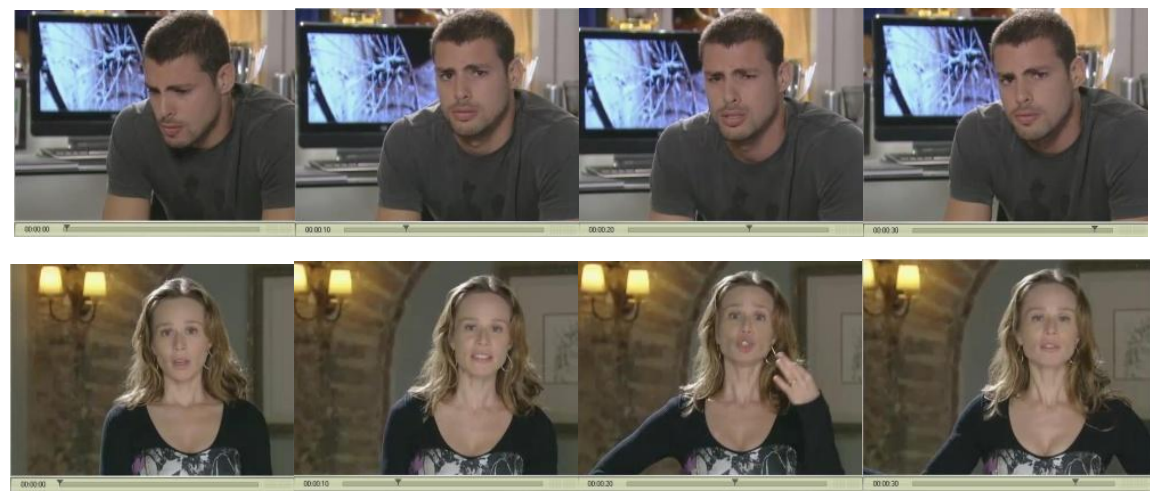

Figura 1 : exemplos de duas cenas estendidas (dez segundos entre frames). 
No jogo cênico da arte dramática, no teatro, cinema, TV ou internet, vemos a dança da transparência versus opacidade, do parecer frente ao aparecer, da dúvida entre mimesis ou aparência. "O Homo fictus é e não é equivalente ao Homo sapiens, pois vive segundo as mesmas linhas de ação e sensibilidade, mas numa proporção diferente e conforme avaliação também diferente" (Cândido, 2005, p. 63). A relação entre gênero e interpretação se estabelece quando se impõem as regras do próprio gênero e, sabemos, o gênero melodrama é constantemente revisitado por sua ligação ao naturalismo que, invariavelmente, envelhece e, paradoxalmente, rejuvenesce.

Até aqui, realizamos uma observação teórica para apresentar nosso objeto e, a partir de agora, iremos enfocar a experiência específica de construção e manuseio do corpus da pesquisa propriamente. Nas cenas estendidas, os personagens da telenovela, em atuações inéditas, falam em tom confessional com o espectador, na tela do computador, como se olhando em seus olhos. Para Borelli (2011), vemos uma narrativa central em diálogo com "as muitas materialidades audiovisuais" dispersas no site:

Nesse intercâmbio entre fragmentos e narrativa linear, Passione inovou com a produção de cenas exclusivas para a internet, por exemplo, com personagens discorrendo, na homepage, sobre acontecimentos vividos na narrativa televisiva original (BORELLI, 2011, p. 81).

O objetivo do site era ter, conforme declarou a Globo em publicação anterior à estreia, um extenso conteúdo em vídeo na internet, sendo que o site apresentaria "mais cenas da novela e, como um dos grandes diferenciais, vídeos, fotos e textos produzidos exclusivamente para contar a história na internet" 5 . A seguir, pretendemos criar, a partir dessas cenas estendidas de Passione, um modelo de abordagem para manejo de dados textuais, no sentido de sistematizar e operacionalizar conceitos válidos para análises quantitativas, de conteúdo principalmente. Nesse caso, segundo Bardin (2011), em termos de

5 Disponível em Passione estreia nova plataforma de internet no dia 17 de maio. Disponível em: <http://redeglobo.globo.com/novidades/novelas/noticia/2010/04/passione-estreianova-plataforma-de-internet-no-dia-17-de- maio.html>. Acesso em 27 de jun. de 2013, não mais disponível. 
análise de conteúdo, estaríamos lidando com métodos, ou seja, organização, codificação, categorização, inferência e informatização das análises.

\section{Nuvem de tags}

Um dos desafios que se impôs durante o desenvolvimento de nossa dissertação de mestrado ${ }^{6}$ dizia respeito à metodologia a ser utilizada para a análise das cenas estendidas de Passione do corpus. O processo metodológico como um todo se desdobrou de maneira simultânea e complementar: (a) no acompanhamento da telenovela pela TV analógica e digital; (b) no acompanhamento do site antes, durante e após a exibição da telenovela com interatividade pessoal; (c) no acompanhamento de outras plataformas; (d) no acompanhamento das cenas estendidas.

O corpus da pesquisa a que esse artigo se refere, especificamente, é composto pelas 211 cenas estendidas de Passione que estavam no ar, no site, na Aba Personagens, no mês de junho de 2011 e que foram organizadas e transcritas para análise. No primeiro momento em que transcrevemos tais cenas, compilamos um extenso material e, para torná-lo manuseável, experimentamos o sistema de nuvem de tags como solução de categorização visual para sua operacionalização tanto em termos de técnicas quantitativas (tabulação) quanto qualitativas (categorização e análise do material colhido).

As Ciências da Comunicação têm diante de si um desafio no sentido de que, atualmente, fatores tanto externos quanto internos ao texto encontram-se em movimento de expansão e mutabilidade contínuas o que justifica experimentos e testes. Hoje, é fundamental observar o ambiente e a circulação da ficção televisiva brasileira e, imersos nesse percurso experimental, na nossa era incunabular da narrativa transmidiática, ainda temos a tarefa de documentar nosso tempo.

\footnotetext{
${ }^{6}$ LEMOS, Ligia Prezia. Transmidiação, linguagem, discurso e experiência de criação de universo narrativo: $o$ expectador e as cenas estendidas do site da telenovela Passione. Dissertação de mestrado. Escola de Comunicações e Artes, Universidade de São Paulo, USP, 2012. Disponível em: $<$ http://www.teses.usp.br/teses/disponiveis/27/27152/tde-04032013-112336/ptbr.php $>$. Acesso em 15 de dez. de 2014.
} 
A nuvem de tags é utilizada para a categorização visual de sites, imagens, títulos e outras etiquetas ou rótulos. É, portanto, uma representação visual que oferece possibilidade de classificação hierárquica, quantitativa. Nesse trabalho, a nuvem de tags foi utilizada para categorizar as palavras do texto, hierarquizadas de maneira proporcional, por incidência.

O objetivo foi testar um dos possíveis modelos de ferramenta de análise disponíveis em um momento histórico em que os existentes já não dão conta da complexidade das comunicações e o polo da produção também começa a pesquisar e testar diferentes possibilidades criativas. A constante renovação dos referenciais teóricos para o tema assim como a necessidade de construção de um novo olhar sobre o objeto são a dificuldade e, simultaneamente, o desafio da presente pesquisa. A nuvem de tags oferece um modelo de classificação eficiente por ser um método em que a indexação pode ser definida como um conjunto de procedimentos com objetivo de expressar ou representar o conteúdo temático de documentos e suas linguagens com o intuito de uma recuperação posterior.

Ainda que receba diferentes nomenclaturas (indexação; catalogação de assunto; tagging; etiquetagem; etc.) o ato de representar um documento através de um conceito é de mesma natureza nos diferentes contextos - físico e digital (GUEDES e DIAS, 2010, p. 42).

Usualmente a nuvem de tags apresenta os itens de conteúdo de um website e revela, proporcionalmente, pelo tamanho da fonte, a quantidade aparente desse conteúdo. O experimento aqui apresentado trata, pois, o conjunto das cenas estendidas de Passione como se fosse um website e, a partir de então, procura revelar, proporcionalmente, pelo tamanho da fonte, a quantidade de determinado conteúdo apresentado nas cenas. Nesse sentido, nossa proposta é que a nuvem de tags seja utilizada na fase de pré-análise do material (Bardin, 2011) em que este é organizado para formar o corpus de pesquisa. Segundo Bardin (2011), a presença ou ausência de certos elementos, como palavras e temas, pode ser um fator significativo da análise, assim como a frequência em que aparece dada unidade de registro. No inventário e classificação de conteúdo a nuvem de tags pode auxiliar no processo de escolha de categorias que adotem o critério semântico (temas) e sintático (verbos, 
adjetivos e pronomes). Segundo Brandt e Medeiros (2010: 120), o processo de etiquetagem pode apresentar falhas em termos de "falta de padronização", por essa razão, estipulamos alguns procedimentos, principalmente no sentido de eliminar partículas como preposições, conjunções, artigos, buscando, assim, um vocabulário controlado com vistas à realização de posterior análise de conteúdo. Devido a nosso objetivo ser metodológico, não nos aprofundaremos em questões como polissemia, sinonímia, variações do nível básico (Golder e Huberman, 2005), assim como não deixaremos de considerar os termos, digamos, em italiano - um dos núcleos dramáticos da telenovela, a família Mattoli e seus agregados, expressava-se na língua italiana, ou melhor, em uma espécie de combinação do português com o italiano. Cumpre, ainda, estabelecer que não contemplamos a função localizadora, por hiperlinks, que uma nuvem de tags pode proporcionar por não ser esse nosso objetivo.

\section{Procedimentos propostos}

\section{Transcrição}

Após fazer o download e salvar os pequenos vídeos que estavam no ar, no site7, na $A b a$ Personagens, no mês de junho de 2011, apenas para utilização nessa pesquisa, transcrevemos as falas dos 43 personagens das 211 cenas estendidas de Passione ${ }^{8}$, com maior ou menor número de cenas conforme observamos no Gráfico 1.

7Site disponível apenas como referência em: <http://tvg.globo.com/novelas/passione.html>. Acesso em 25 de maio de 2013, não mais disponível.

${ }^{8}$ Nessa pesquisa, utilizamos software player de música e vídeo por meio dos programas RealPlayer (RealNetworks) - player de vídeo, gratuito, que permite baixar, assistir e organizar vídeos (Disponível em: < http://br.real.com/ > . Acesso em 15 de dezembro de 2014) e QuickTime (Apple) - reprodutor de mídia da Apple para grande variedade de formatos de arquivos multimídia (Disponível em: <http://www.apple.com/br/quicktime/>. Acesso em 15 de dezembro de 2014). 


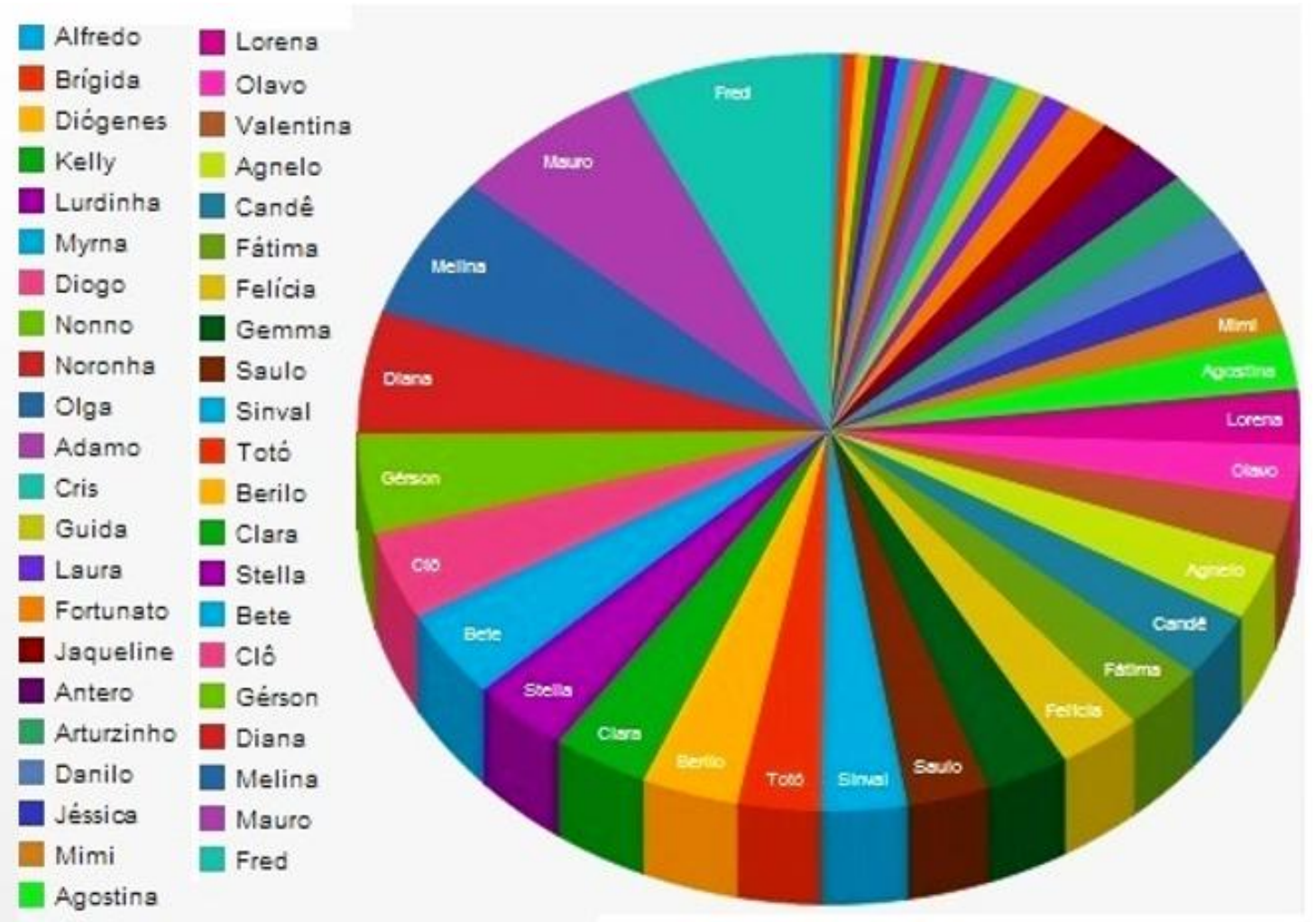

Gráfico 1: Quantidade de cenas estendidas, por personagem.

Personagens como Alfredo, Brígida e Kelly participaram de apenas uma cena estendida enquanto Fred, Mauro e Melina participaram de diversas: 15, 14 e 12 respectivamente.

\section{Organização sequencial}

As transcrições das cenas foram dispostas em sequência crescente, por personagem, ou seja, nossa compilação se inicia com as cenas estendidas de personagens com apenas uma cena e termina com as 15 cenas do personagem Fred.

\begin{tabular}{|c|l|}
\hline & \multicolumn{3}{|c|}{ Eu tenho certeza que o Antero está saindo com aquela italiana } \\
Cena & que contou do filho da Bete. Ele anda muito serelepe \\
ultimamente. Sabe que ele me chama de Hitler de saia? Ele \\
(BRÍGIDA) & $\begin{array}{l}\text { acha que eu estou me metendo muito na vida dele. Pois bem, } \\
\text { ele que me aguarde. Ele que me aguarde que eu estou } \\
\text { preparando uma para ele. Mal sabe o que estou preparando! }\end{array}$
\end{tabular}

Figura 2: Exemplo de transcrição. 


\section{Criação de parâmetros para confecção das nuvens}

Com o objetivo de eliminar possíveis ruídos, estipulamos cinco parâmetros gerais para a confecção das 211 nuvens:

$>\quad$ Digitação da fala inalterada, coloquial.

$>\quad$ Remoção de artigos, conjunções, palavras comuns em português (a, por, que, em, no, um, uma...).

$>\quad$ Utilização de fonte Teen.

$>\quad$ Utilização de layout horizontal.

> Utilização de paleta de cores em tons de cinza com ligeira variação.

Após a transcrição e readequação do texto de cada cena aos parâmetros estipulados, geramos nuvens de palavras/tags no site Wordle 9.

\section{Confecção das nuvens}

As nuvens são, portanto, a representação de uma lista hierarquizada visualmente, com fins de classificação, em que a quantidade maior ou menor de aparições de determinado termo é dada proporcionalmente pelo tamanho da fonte. As nuvens também foram dispostas em sequência crescente, por personagem.

\begin{tabular}{|c|c|}
\hline $\begin{array}{c}\text { Cena estendida } \\
\text { (BRÍGIDA) }\end{array}$ & $\begin{array}{l}\text { Eu tenho certeza que o Antero está saindo com aquela } \\
\text { italiana que contou do filho da Bete. Ele anda muito serelepe } \\
\text { ultimamente. Sabe que ele me chama de Hitler de saia? Ele } \\
\text { acha que eu estou me metendo muito na vida dele. Pois } \\
\text { bem, ele que me aguarde. Ele que me aguarde que eu estou } \\
\text { preparando uma para ele. Mal sabe o que estou preparando! }\end{array}$ \\
\hline $\begin{array}{l}\text { Palavras em } \\
\text { destaque: } \\
\text { PREPARANDO } \\
\quad \text { AGUARDE }\end{array}$ & 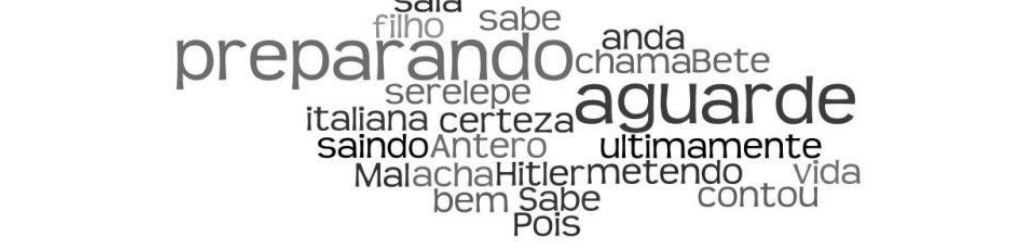 \\
\hline
\end{tabular}

Figura 3: Exemplo de transcrição e nuvem

${ }_{9}$ Disponível em <http://www.wordle.net> com acesso em dez. de 2014. 
Destacamos, com uma anotação à esquerda, o termo - ou termos - com maior destaque em cada nuvem.

\section{Parâmetros de destaque}

Para destacar a palavra mais utilizada em cada nuvem, foi necessário definir novos parâmetros para lidar com as variáveis surgidas: a primeira, em que deixamos sem indicação de destaque quando o resultado visual não foi relevante e, a segunda, em que estipulamos o máximo de quatro destaques. Temos, então, três possibilidades de destaques: (a) resultado visual relevante, que seria o esperado; (b) sem resultado relevante, quando todos os termos foram mencionados apenas uma vez; e (c) com múltiplos resultados.

Pelo fato de havermos gerado uma nuvem para cada cena estendida, o material resultou volumoso ${ }^{10}$ e, por essa razão, apresentamos abaixo apenas exemplos dessas três variáveis:

a. Resultado visual relevante:

\begin{tabular}{|c|c|}
\hline $\begin{array}{c}\text { Cena } \\
\text { estendida } \\
\text { (CRIS) }\end{array}$ & $\begin{array}{l}\text { Ai, me dá uma dor no coração de ver a Diana sofrendo desse } \\
\text { jeito. Pô, parecia que eles iam dar certo, sabe? Mesmo com essa } \\
\text { pressa toda pra se casar! Será que a Diana não está sendo muito } \\
\text { afoita? Já que eles casaram, era melhor que eles trabalhassem } \\
\text { essa relação, né? Ah, mas também! Qual é a do Gérson, hein? } \\
\text { Bom... se a Diana, que é mulher dele, não entende o cara, } \\
\text { imagina eu, né? }\end{array}$ \\
\hline $\begin{array}{c}\text { Palavras em } \\
\text { destaque: } \\
\text { DIANA }\end{array}$ & 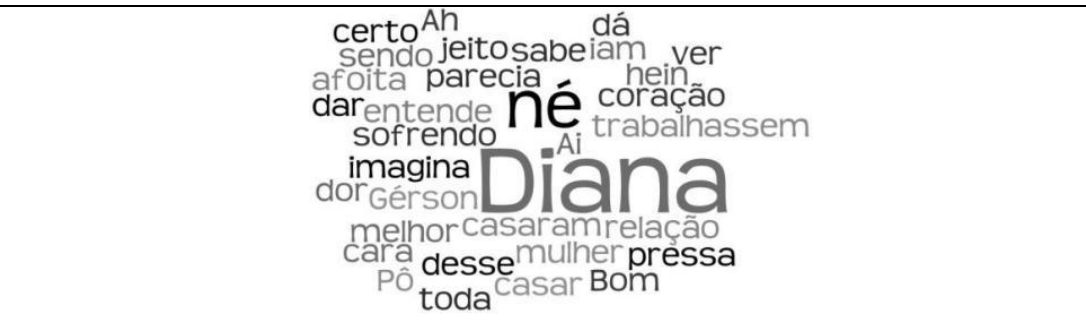 \\
\hline
\end{tabular}

b. Sem resultado relevante:

10 Material completo da presente pesquisa (transcrições e nuvens das 211 cenas estendidas de Passione) disponível em:

<https://docs.google.com/document/d/1qUodDTdPZCikS9haT65bcUCet7LJ8oaW8d3 h7_jugbY/edit?usp=sharing > Acesso em 15 de dez. de 2014. 


\begin{tabular}{|c|c|}
\hline $\begin{array}{l}\text { Cena estendida } \\
\text { (ARTURZINHO) }\end{array}$ & $\begin{array}{l}\text { Nem na hora do barraco a milady perde o glamour. É uma } \\
\text { deusa! Eu queria tanto ajudar ela agora mas, sinceramente, } \\
\text { eu acho que esse casamento está morto. E enterrado. Com } \\
\text { uma vela em cima. Eu não ia agüentar viver levando patada } \\
\text { desse jeito. Não sei como é que os dois não percebem. } \\
\text { Credo! Deus que me perdoe! }\end{array}$ \\
\hline $\begin{array}{c}\text { Palavras em } \\
\text { destaque: } \\
-\end{array}$ & 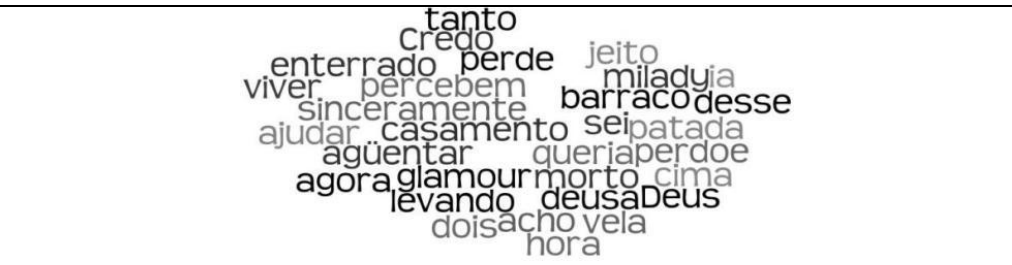 \\
\hline
\end{tabular}

c. Múltiplos resultados visuais (máximo de quatro):

\begin{tabular}{|c|c|}
\hline $\begin{array}{c}\text { Cena } \\
\text { estendida } 1 \\
\text { (DANILO) }\end{array}$ & $\begin{array}{l}\text { Quem diria que o meu irmão, um moleque, ia me dar uma lição } \\
\text { de vida? Eu nem sei como tudo isso aconteceu mas parece que } \\
\text { foi assim, num piscar de olhos que eu deixei o Danilo, campeão } \\
\text { de ciclismo, aquele cara cheio de mina atrás, no passado, lá } \\
\text { atrás... e virei outra pessoa. Eu estou ligado, estou em outra, } \\
\text { estou... estou diferente. E também estou me lixando para o } \\
\text { perigo. Agora o que eu quero é curtir o quanto a vida puder me } \\
\text { dar. Isso sim! }\end{array}$ \\
\hline $\begin{array}{c}\text { Palavras em } \\
\text { destaque: } \\
\text { ATRÁS } \\
\text { VIDA } \\
\text { DAR } \\
\text { OUTRA }\end{array}$ & 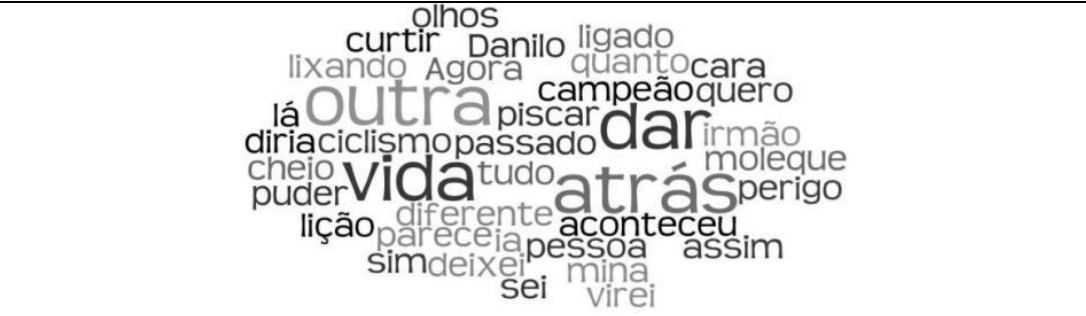 \\
\hline
\end{tabular}

\section{Nuvem total}

A partir da reunião das palavras em destaque nas 211 cenas estendidas foi realizado o levantamento das palavras preponderantes, o que resultou na listagem a seguir que, por sua vez, possui a maleabilidade de passar pelo filtro de novos parâmetros e, nesse caso, geraria novas nuvens com possibilidades específicas de análise de conteúdo a partir do ponto de vista quantitativo.

Zia Preparando Aguarde Doação Saulo Verdade Mimi Agostina Fred Mimi Nunca Fazer Io Agnelo Diana Vai Rogério Noronha Mauro Diana Ainda Vai Casa Vou Rogério Aqui Vai Gemma Deu Ajudar Stela Saulo Quer Milady Ai Bem Vou Outra Vida Dar Atrás Clara Fica Hora Quiser Sei Deus Fragoloni Fazer Berilinho Plano Resgate Vai Questa Nonno Mio Estão Mais Nonno Io Fazer Vai Quello Berilo Agostina Berilo Brasile Mimi Mordomo Ma Mimi Io Ainda Mãe Traição Ter Devia Mãe Laura Pai Sei Danilo Mãe 


\begin{abstract}
Souber Italiano Parece Brincadeira Panterona Jaque Papagaio Aí Vou Deus Outra Ótimo Criar Achando Sempre Ser Bom Clara Sabe Vou Vida Séria Ragazza Família Vai Stela Stela Quer Stela Lorena Io Vou Vou Filho Santo Expedito Outro Safado Nada Vou Mãe Vai Gente Pai Pai Né Comigo Cara Alguém Juro Coisa Sinval Vai Marido Certo Né Deus Vai Verdade Fátima Ai Reparar Mim Totó Vida Gente Lá Squifozza Madonna Chiara Sei Totó Giorno Felícia Madonna Io Empresa Grandes Ver Fred Vai Fred Aqui Bem Ter Limpo Vou Tomei Nada Pensar Ver Ter Mãe Ainda Hora Gemma Santo Dio Podia Moça Chiara Mete Agnelo Felícia Io Tentei Fazer Posso Duas Fico Dois Perto Consigo Casado Aqui Queria Atitude Esposa Deixar Ser Feliz Né Vai Vou Vida Kelly Vai Vou Qualquer Tanta Coisa Fred Consigo Saulo Sei Aqui Culpa Tudo Acho Pai Ser Especial Lá Homem Preciso Mãe Família Cartas Lobato Sangue Jantar Jardim América Olavo Jaque Nanci Cueca Porque Parar Aqui Nesse Olavo Jéssica Causa Vou Dizer Fofô Jaque Dou Muita Acho Diana Nunca Agora Vou Única Conversar Diana Morte Saulo Pai Mãe Stela Vou Vai Pagar Tudo Mauro Melina Mim Computador Gente Casamento Privacidade Errado Mauro Cara Pensando Jeito Desse Gérson Mauro Vida Melina Dessa Saco Menos Maior Desfile Moleque Todo Esperança Acho Criança Né Mauro Queria Mauro Gente Queria Acho Vai Tão Mauro Vou Mundo Deixa Tudo Quero Né Engraçado Fácil Vai Acho Aqui Saulo Ter Empresa Gente Bete Dona Cima Vou Melina Empresa Stela Dinheiro Vai Bem Ações Empresa Vai Coisa Acionistas Bons Vou Cara Clara Verdade Lado Ter Sei Agora Hora Saulo Jeito Vai Gouveia Besta Ter Tudo Saulo Acha Gente Ter Mãe Ainda Quer Deve Estar Saber Secretária Onde Gosto Dei Danar Mim
\end{abstract}

Figura 4: Listagem das palavras em destaque.

Em nosso caso, a partir da listagem completa das palavras em destaque, a nuvem resultante foi:

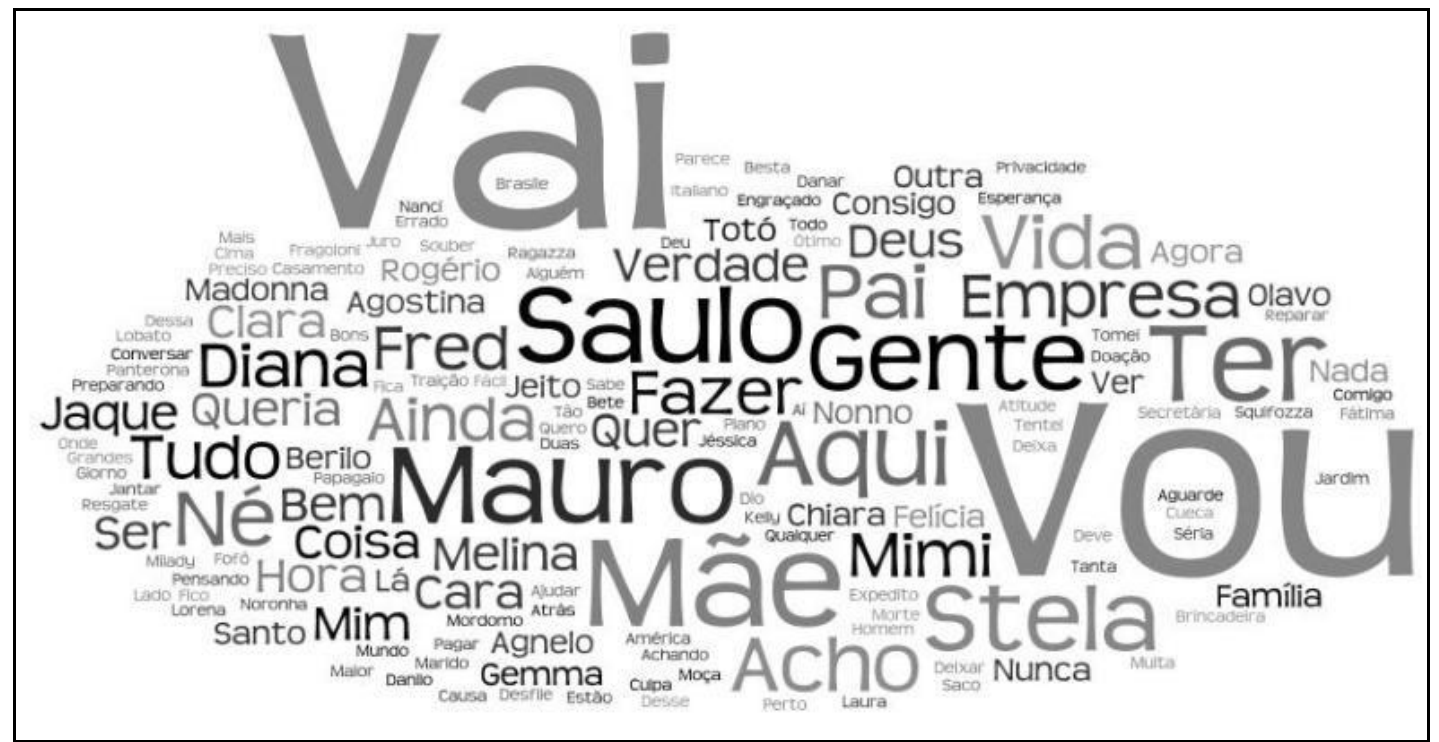

Figura 5: Nuvem das palavras mais freqüentes no conjunto das falas das cenas estendidas de Passione.

\title{
7. Novos parâmetros
}

A utilização da nuvem de tags permite criar parâmetros de seleção se houver a necessidade de gerar novas nuvens com possibilidades específicas de 
análise de conteúdo. Por exemplo, a criação de uma nuvem que destacasse apenas os verbos, ou apenas nomes próprios e assim por diante, auxiliando, como já mencionado, no processo de escolha de categorias que adotem o critério semântico (temas) e sintático (verbos, adjetivos e pronomes).

\section{Considerações finais}

Mesmo sem criar novos parâmetros, o procedimento de utilização da nuvem de tags possibilita iniciar uma primeira análise de conteúdo geral, sendo possível verificar, no exemplo apresentado, quais personagens mais citados pelos outros (Saulo, Mauro), quais verbos mais utilizados (vai, vou), quais locais (empresa), expressões (né) e assuntos (vida, pai) mais mencionados.

As cenas estendidas pertencem a um sistema de linguagem que pretende contar e ampliar as histórias ficcionais de nosso tempo pelos meios agora disponíveis. A nuvem de impressões que se depreende delas pode ser ponto de partida interessante para análises e inferências num momento em que a constante renovação dos referenciais teóricos assim como a necessidade de construção de um novo olhar sobre objetos tão fluidos são a dificuldade e, ao mesmo tempo, a característica desafiadora da pesquisa em comunicação. A nuvem de tags é uma ferramenta que pode auxiliar na categorização da fluidez desse - e de outros - conteúdos.

\section{Referências}

ANDERSON, Benedict. Comunidades imaginadas: reflexões sobre a origem e a difusão do nacionalismo. São Paulo: Companhia das Letras, 2008.

BAKHTIN, Mikhail. Estética da criação verbal. São Paulo: Martins Fontes, 2010.

BARDIN, Laurence. Análise de conteúdo. São Paulo: Edições 70, 2011.

BORELLI, Silvia. Migrações narrativas em multiplataformas: telenovelas Ti-ti-ti e Passione. In: LOPES, Maria Immacolata Vassallo de (org.) Ficção televisiva transmidiática no Brasil: plataformas, convergência, comunidades virtuais. (Coleção Teledramaturgia - Volume 2. Porto Alegre: Sulina, 2011.

BRANDT, Mariana; MEDEIROS, Marisa B. B. Folksonomia: esquema de representação do conhecimento?. Transinformação, Campinas, v. 22, n. 2, p. 111-121, maio/ago. 2010. 
CÂNDIDO, Antônio. A personagem do Romance. In: CÂNDIDO, Antônio et al. A personagem de ficção. São Paulo: Perspectiva, 2005.

COMPARATO, Doc. Da criação ao roteiro: teoria e prática. São Paulo: Summus, 2009.

GOLDER, Scott A.; HUBERMAN, Bernardo A. The structure of collaborative tagging systems. 2005. Disponível em http://arxiv.org/abs/cs.DL/0508082. Acesso em: 12/05/2012.

GUEDES, Roger M.; DIAS, Eduardo J. W. Indexação social: abordagem conceitual. Revista ACB: Biblioteconomia em Santa Catarina, Florianópolis, v. 15, n. 1, p. 39-53, jan./jun. 2010. Disponível em: http://revista.acbsc.org.br/racb/article/view/686. Acesso em 25/04/2012

JENKINS, Henry. Cultura da convergência. São Paulo: Aleph, 2009.

LEMOS, Ligia Prezia. Transmidiação, linguagem, discurso e experiência de criação de universo narrativo. Dissertação de mestrado. Escola de Comunicações e Artes, Universidade de São Paulo, USP, 2012.

LOPES, Maria Immacolata Vassallo de. Pesquisa de comunicação: questões epistemológicas, teóricas e metodológicas. Revista Brasileira de Ciências da Comunicação, São Paulo, v.27, n.1, p. 13-39, jan./jun. 2004. Disponível em: https://revistas/index.php/revistaintercom/article/download/. Acesso em maio de 2012.

LOPES, Maria Immacolata Vassallo de (org.) Ficção televisiva transmidiática no Brasil: plataformas, convergência, comunidades virtuais. (Coleção Teledramaturgia - Volume 2. Porto Alegre: Sulina, 2011.

LOPES, Maria Immacolata Vassallo de \& Orozco Gomes, Guillermo (coords.). Qualidade na ficção televisiva e participação transmidiática das audiências. OBITEL -Anuário 2011. Rio de Janeiro: Ed. Globo, 2011.

MOTTER, Maria Lourdes; MUNGIOLI, Maria Cristina Palma. Serialidade: o prazer de re -conhecer e pré -ver. Anais. XXIX Congresso Brasileiro de Ciências da Comunicação - UnB - 6 a 9 de setembro de 2006. Disponível em: http://www.portcom.intercom.org.br/pdfs/12895613101841687758486373 378452364370.pdf. Acesso em 10 de junho de 2013.

MURRAY, Janet H. Hamlet no Holodeck: o futuro da narrativa no ciberespaço. São Paulo: Itaú Cultural: UNESP, 2003. 